\title{
Implantable microdevice with integrated wireless power transfer for thermal neuromodulation applications
}

\author{
J. Fernandes, H. Dinis, L. M. Gonçalves, P. M. Mendes \\ CMEMS, University of Minho, Guimarães, Portugal
}

\begin{abstract}
Medication resistant neurological and psychiatric disorders, RNPD, are devastating multicausal chronic diseases that cannot be adequately controlled using conventional pharmaco and/or psychotherapies, being epilepsy a well-known RNPD. Wireless biomedical device availability is growing at an impressive rate, and the systems' miniaturization, integration and complexity is also increasing, unveiling new therapies based on such new devices. This paper presents a new wireless implantable device as a solution for thermal neuromodulation of brain cells, which can be used to treat or study the brain's behavior when cooled down. The obtained results show that, despite these systems' potential to be power hungry, they may operate within acceptable electrical power values, while reaching the required neuromodulation temperatures.
\end{abstract}

Keywords - implantable device; thermal neuromodulator; microcooler; peltier effect; wireless biomedical device.

\section{INTRODUCTION}

Advances in medicine have long been supported by the availability of new technological solutions, where microdevices have been playing an important role. Implantable medical devices are becoming smaller, and new solutions on treatment, diagnostics, and even on the replacement of some normal functions, are becoming a reality in the biomedical field [1]. This market is expected to have a high growth rate, while it contributes with some innovative approaches that can revolutionize all medical treatments and diagnostics [2]. Such solutions demand for ever smaller designs, more efficient electronics, and complex systems with sensors and actuators, all with integrated wireless solutions. Such implantable devices are envisaged in several different usages, where smaller sizes could bring new applications to places which, nowadays, are impossible to reach, enabling the monitoring or treatment of several conditions, including neurological disorders, cardiovascular problems, and ophthalmologic diseases [1].

Epilepsy is a well-known disease where 25 to 30 percent of the patients continue to experience seizures even after the best available therapy [3, 4], surgical treatment included [5]. One method that was proposed with potential to treat medication RNPD cases is thermal neuromodulation [6]. Temperature control can change the cells' behavior and there are many different applications where increasing or decreasing the temperature can promote the modulation of the neurons' electrical signals. With this kind of neuromodulation, it is expected, for example, to suppress

This work has been supported by FCT (Fundação para a Ciência e Tecnologia) in the scope of the project PTDC/EEITEL/5250/2014, project PTDC/CTM-NAN/5414/2014 and under grant SFRH/BD/100649/2014.

José Fernandes, Hugo Dinis, Luís Gonçalves and Paulo Mendes are with CMEMS - Universidade do Minho, Guimarães, Portugal (e-mail: id4951@alunos.uminho.pt, paulo.mendes@dei.uminho.pt). epileptic seizures [3] or to test thermal stimulations on single neurons in vitro [7]. To be successful, such device must fit inside the smallest volume possible, in a way that it allows a completely autonomous system operation.

Figure 1 shows the envisaged full system architecture for a technology that is able to modulate neuronal activity, which is based on an external control system and an implanted device. In this paper, we discuss the development of a miniaturized wireless implantable microsystem for thermal neuromodulation. The proposal consists on the use of a thermoelectric microcooler based on Peltier effect as the cooling device, integrated with a RFCMOS chip that will host control, power, and communication electronics. Since the microcooler, when compared to other microdevices, is expected to be power hungry, this paper develops a solution to integrate an antenna, with low volume penalty, that allows wireless communications and wireless power transfer.

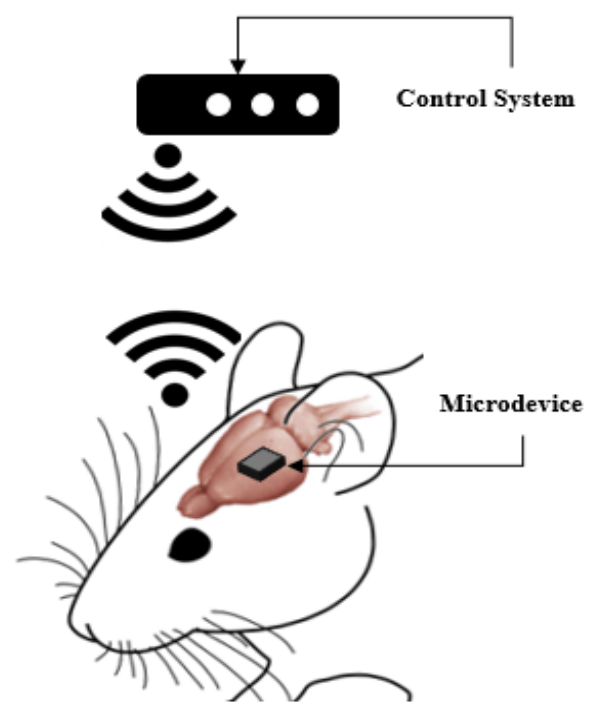

Figure 1. Thermal neuromodulation by wireless implanted microdevices.

This paper presents the first results in the development of the small microdevice. It starts with the simulated thermal effects of one small peltier device inserted in brain cells, and the results for different conditions are shown and analyzed in the last section. Then, a first approach to the design and simulation of one small heat sink that works as an antenna is also demonstrated with both simulated and measured results.

\section{Thermal NeUROMOdULATOR}

The main objective of this project is centered on the development of a wireless implantable low power thermal microdevice to achieve neuromodulation on rat brains. The thermoelectric module will receive power from an RF source to cool down the required site using the Peltier effect. 


\section{A. System architecture}

The full system concept is presented in figure 1, where the overall objective of this project is shown: to implant a wireless temperature control system for rat brain activity thermal modulation. The internal module is composed by three major parts: the signal receptor (antenna), the RFCMOS electronic circuit, and the microcooler actuator. However, while cooling in one side, this method can also induce irreversible thermal damage on cells in the vicinity of the hot side, so a complete control of the temperatures and exposure times is imperative. Moreover, to keep the hot temperature bellow safe levels, it is necessary to include a heat sink, which is a rather bulky device. The heat sink, together with the required antenna for wireless power transfer, are the devices that required special design considerations due to their volume. This way, to minimize the volume penalty, one key feature was to include the antenna in a way it will also work as a heat sink for the hot side of the microcooler.

Figure 2 shows the architecture of the implantable device. The goal was to develop a solution with a wireless link that could operate at high frequencies (this way the antenna may become smaller), but with high enough efficiency, since this microsystem is expected to be powered wirelessly, in order to minimize its dependency on batteries.

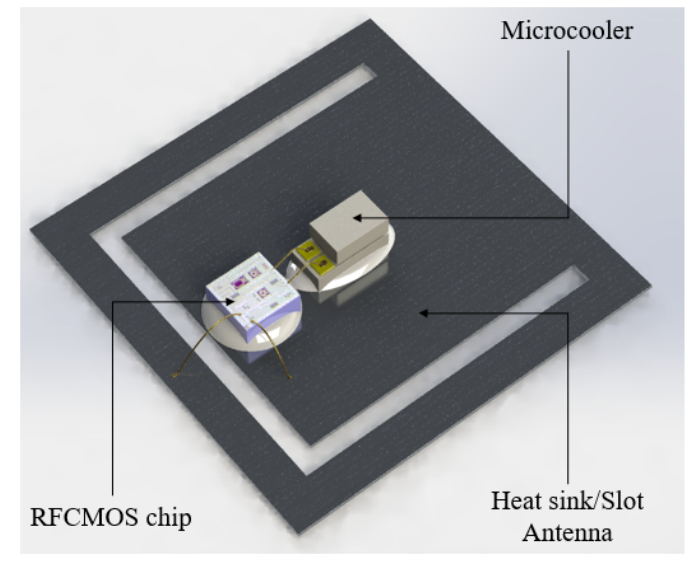

Figure 2. Proposed microdevice for thermal applications.

The core component of this proposal is the thermal actuator, since it will be responsible for thermal neuromodulation. However, attention should also be given to the electronic circuit that will convert the received RF signal to a DC signal which will, then, be used to drive the microcooler. With the use of amplifiers, filters and rectifiers, a DC signal can be extracted to power-up the system and drive the actuator. This circuit has to be efficient, lossless, low-power, and it should be able to deal with the high levels of power required to drive the microcooler.

\section{B. Temperature control and power requirements}

The temperature control will be assured by a microcooler device. This device's working principle is the thermoelectric effect, which states that when an electrical current is injected, the device will stimulate temperature changes by heating up on one side of the device and cooling down on the opposite one. Nowadays, small microcooling devices that are able to operate with low currents and promote significant temperature gradients between their two sides are available.
The microcooler device selected was the Micropelt ${ }^{\circledR}$ MPCD403. That device produces temperature differences up to $30{ }^{\circ} \mathrm{C}$ between the hot and the cold side, by injecting less than $200 \mathrm{~mA}$. This device was also chosen because it measures only $2 \mathrm{~mm}$ of length, being suitable to fit in a rat's head, where it will be used for the first experiments.

As we can see, the power needs of the proposed microsystem are highly dependent on the power required by the microcooler. Consequently, the first step will be to model and understand the power requirements to reach the required temperatures.

\section{SySTEM MODELING AND DESIGN}

The first step of the work was to develop and calibrate a model capable of mimicking the datasheet properties of the thermoelectric microcooler that is proposed in the project's implementation.

\section{A. Microcooler modeling and simulation}

The model was designed with the same dimensions as the microcooler device and with materials commonly used in thermoelectric applications. So, the microcooler device's plates were made of alumina (electric isolator and a good thermal conductor), while the pads and the thermoelectric material were made of copper and bismuth telluride $\left(\mathrm{Bi}_{2} \mathrm{Te}_{3}\right)$, respectively. The model is presented in figure 3 . With this model for thermoelectric simulations, it is possible to simulate interactions between the microcooler and, for example, brain cells. Applying the thermoelectric equations, including the Seebeck, the Peltier and the Joule effects, an accurate thermoelectric simulation may be achieved only if the correct material properties are known. Table I shows values of material properties used in the present study.

TABLE I. MATERIALS USED FOR MICROCOOLER SIMULATION.

\begin{tabular}{|c|c|c|c|c|c|}
\hline \multirow{2}{*}{ Material } & \multicolumn{5}{|c|}{ Variables } \\
\cline { 2 - 6 } & $\begin{array}{c}\boldsymbol{C p} \\
(\boldsymbol{J} /(\mathbf{k g} . \boldsymbol{K}))\end{array}$ & $\begin{array}{c}\boldsymbol{\rho} \\
(\boldsymbol{k g} / \boldsymbol{m} \mathbf{3})\end{array}$ & $\begin{array}{c}\lambda \\
(\boldsymbol{W} /(\boldsymbol{m} . \boldsymbol{K}))\end{array}$ & $\begin{array}{c}\boldsymbol{S} \\
(\boldsymbol{V} / \mathbf{K})\end{array}$ & $\begin{array}{c}\boldsymbol{\sigma} \\
(\mathbf{S} / \boldsymbol{m})\end{array}$ \\
\hline Alumina & 900 & 3900 & 27 & N.A. & N.A. \\
\hline Copper & 385 & 8700 & 400 & $6.5 \mathrm{e}-6$ & $5.99 \mathrm{e} 7$ \\
\hline Bi2Te3 & 154 & 7700 & 1.75 & $\pm 170 \mathrm{e}-6$ & $0.99 \mathrm{e} 5$ \\
\hline $\begin{array}{c}\text { Brain } \\
\text { Tissue }\end{array}$ & 3700 & 1050 & 0.527 & N.A. & N.A. \\
\hline
\end{tabular}

$C p$ is the heat capacity, $\rho$ is the density of the material, $\lambda$ is the thermal conductivity, $S$ is the seebeck coefficient, and $\sigma$ is the electrical conductivity. Brain characteristics were obtained from $[8,9]$, while other materials' were standard values, adjusted to the microcooler device when necessary. The microcooler device was simulated with the aforementioned thermoelectric equations in order to provide approximate results to those presented in the datasheet. In figure 3 , it is possible to compare the achieved temperature difference between the microcooler plates, both for the data presented on the datasheet and the results obtained in simulation.

In figure 3, the green curves represent the temperature difference (between the hot side and the cold side) presented in the device's datasheet, for a hot side temperature of $40{ }^{\circ} \mathrm{C}$, 
and the blue lines represent the simulated results, in equivalent conditions. The dashed lines represent the microcooler with a heat load of $0 \mathrm{~mW}$ in the cold side, and the solid lines represent the same conditions but with a heat load of $125 \mathrm{~mW}$ on the cold side. The brain heat load value (gray line) can fit between $0 \mathrm{~mW}$ and $125 \mathrm{~mW}$. Therefore, it is expected that the behavior of the simulated microcooler will be approximately equivalent to the real application scenario.

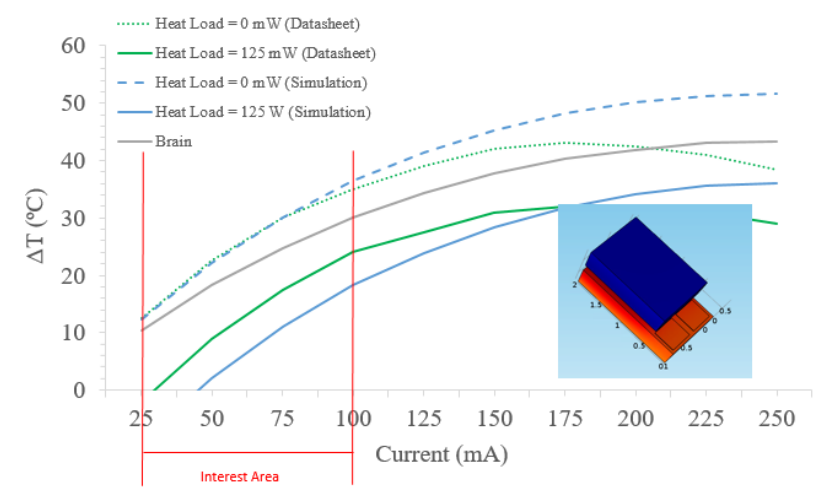

Figure 3. Simulation results versus datasheet for MPC-D403 model, under relevant heat load conditions.

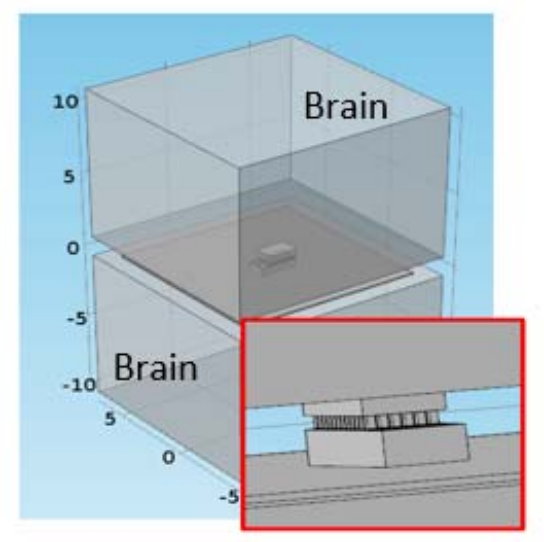

Figure 4. Model used to simulate the microcooler effect when the brain cells are considered as heat load.

\section{B. Neuronal thermal modeling}

After validation of the microcooler element, the brain cells were added, as shown in figure 4, being modeled as blocks of $12 \mathrm{~mm} \times 10 \mathrm{~mm}$, while the microcooler device was placed in between them. It was considered that the microcooler device is insulated in the lateral faces. This means that the sides of the microcooler device don't lose heat, and only the surfaces were exposed to the brain cells. In the brain heat transfer simulations, in order to make it more realistic, the thermal regulation caused by blood flow was considered using a convenient heat flow. Convective heat generated by blood perfusion was considered to be $0.029 \mathrm{~W} / \mathrm{cm}^{3} / \mathrm{K}$ and the metabolic heat was set as $0.025 \mathrm{~W} / \mathrm{cm}^{3}[10]$.

To avoid overheating of nearby neurons on the hot side, the microcooler was attached to a heat sink to diffuse the heat generated over a larger area. Consequently, an aluminum plate with $1 \mathrm{~cm}^{2}$ was added to make the heat extraction. The aluminum heat sink was added to the microcooler's hot side and the full device was placed between brain cells. Since it is well known that a microcooler has an optimal operating point, the model was then used to inject different currents, giving us a perspective of the brain cells' expected temperature gradients. After analyzing figure 3 (and knowing that the brain has a heat load between $0 \mathrm{~mW}$ and $125 \mathrm{~mW}$ ), in order to cool it down to $20{ }^{\circ} \mathrm{C}$, a current between $50 \mathrm{~mA}$ and $100 \mathrm{~mA}$ was expected, so these two currents were simulated for $100 \mathrm{~s}$. It is also known that brain cells can't reach temperatures higher than $43{ }^{\circ} \mathrm{C}$ and bellow $0{ }^{\circ} \mathrm{C}$, as to avoid irreversible thermal damage.

\section{Antenna design and simulation}

In order to wirelessly power the implantable device, an integrated antenna is required. As previously stated, the Peltier module requires a heat sink to ensure proper and safe operation, therefore it was decided to use this heat sink to also operate as an antenna, therefore minimizing the device's size and volume.

As the heat sink is a metal sheet, the most straightforward antenna architecture is the slot antenna, as it allows a minimal reduction of the heat sink's effective area, i.e., an intricate antenna design which required several cuts in the middle of the metal sheet would significantly reduce its heat conductivity and, ultimately, the device's performance.

As a first antenna design iteration, the antenna was fabricated with off-the-shelf materials, namely Rogers RO4003 substrate. The slot was carved on the substrate and copper on the opposite side was etched out. An SMA connector was inserted as shown in figure 5, where a model of the prototype is presented. The slot is $1.1 \mathrm{~mm}$ wide, while the antenna is a square with $13 \mathrm{~mm}$.
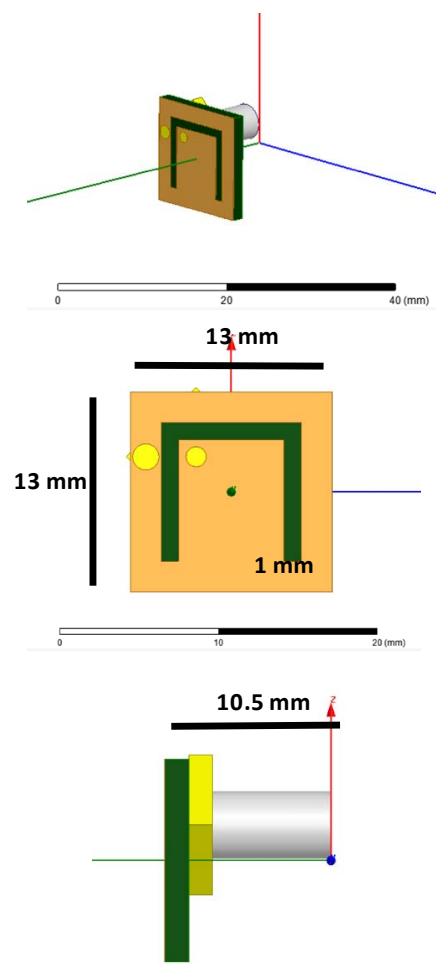

Figure 5. Antenna and connector HFSS model. 
Since the antenna is being designed for operation inside the human brain, its simulations and measurements were performed inside water, as a first approximation to the human brain's dielectric properties, given to its composition being mostly water.

\section{RESUlts AND DISCUSSION}

\section{A. Temperature analysis.}

In figures 6 and 7, the obtained values when injecting $50 \mathrm{~mA}$ and $100 \mathrm{~mA}$, respectively, during 5,30 , and $100 \mathrm{~s}$, are represented. Observing the first results shown in figure 6 , it is possible to see that the hot side temperature has more effect in the cells than the cold side in a short time. Letting the microcooler turned on for long time, the hot side temperature increases, but the cooled area slightly expands. Comparing the $30 \mathrm{~s}$ with the $100 \mathrm{~s}$ exposure instants, we can assume that the cold side differences between them are insignificant. In all cases the temperature didn't exceed $43{ }^{\circ} \mathrm{C}$ and didn't drop below $0{ }^{\circ} \mathrm{C}$, meaning that these experiments won't inflict thermal damage on brain cells. Observing the second case (injection of $100 \mathrm{~mA}$ in the microcooler - figure 7), we can immediately notice that larger cooled areas were achieved with even lower temperatures when compared with the results with $50 \mathrm{~mA}$, but the hot side got hotter, which is easily explained by the Joule effect, as a consequence of more current being injected in the system. This led to a temperature raise on the hot side, where the obtained values were above $43{ }^{\circ} \mathrm{C}$ and, consequently, the brain cells could suffer irreversible damage and even be destroyed, if exposure time is not controlled.

In order to easily find the precise values of temperature that were achieved and the depths at which they were felt, a crosssection was selected right through the center of the microcooler device (defined by the cross section A-A' in figure 6 (a)). In figure 8 , the temperature results are shown, and we can now clearly see that with a $50 \mathrm{~mA}$ current the brain never reached $43{ }^{\circ} \mathrm{C}$. On the cold side it was possible to push areas of the brain down to $20^{\circ} \mathrm{C}$ and to cool $1 \mathrm{~mm}$ of brain tissue bellow $30^{\circ} \mathrm{C}$. It is also possible to say that
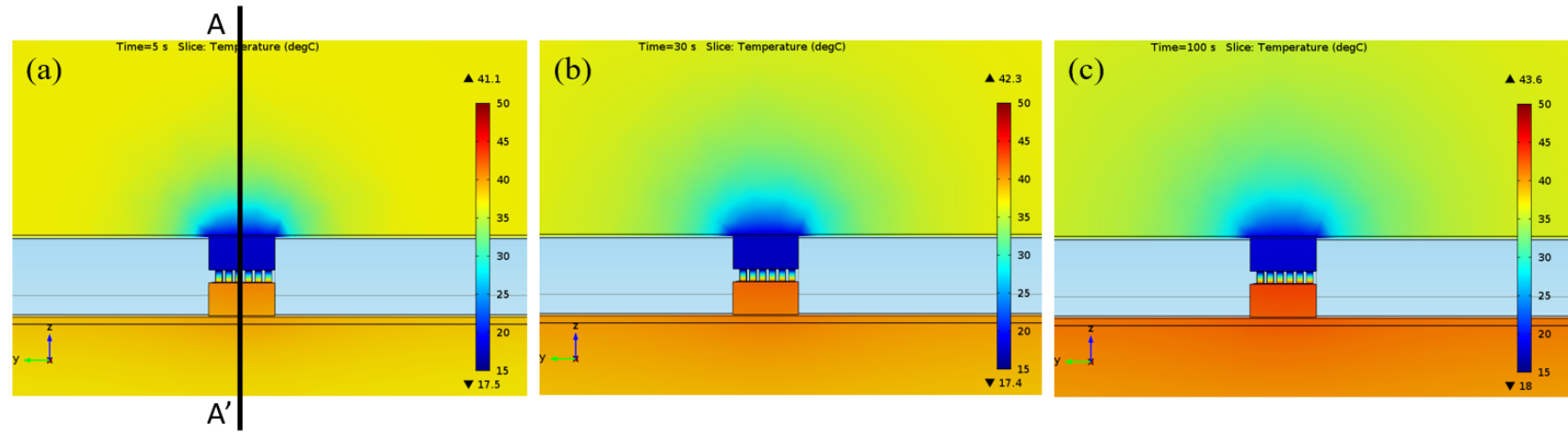

Figure 6. Temperature map on the brain cells with $50 \mathrm{~mA}$ in (a) $5 \mathrm{~s}$ (b) $30 \mathrm{~s} \mathrm{(c)} 100 \mathrm{~s}$.
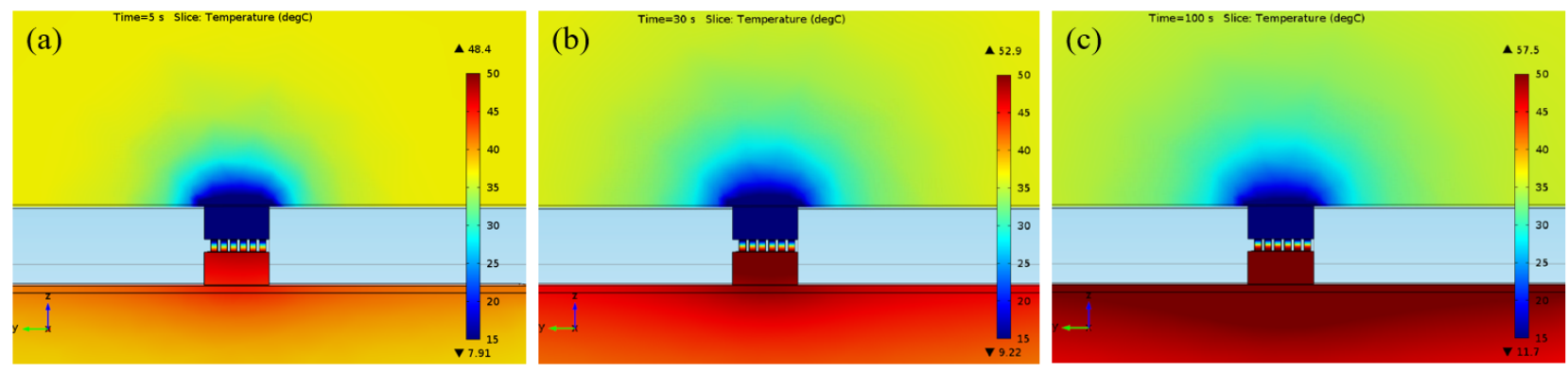

Figure 7. Temperature map on the brain cells with $100 \mathrm{~mA}$ in (a) $5 \mathrm{~s}$ (b) $30 \mathrm{~s}$ (c) $100 \mathrm{~s}$
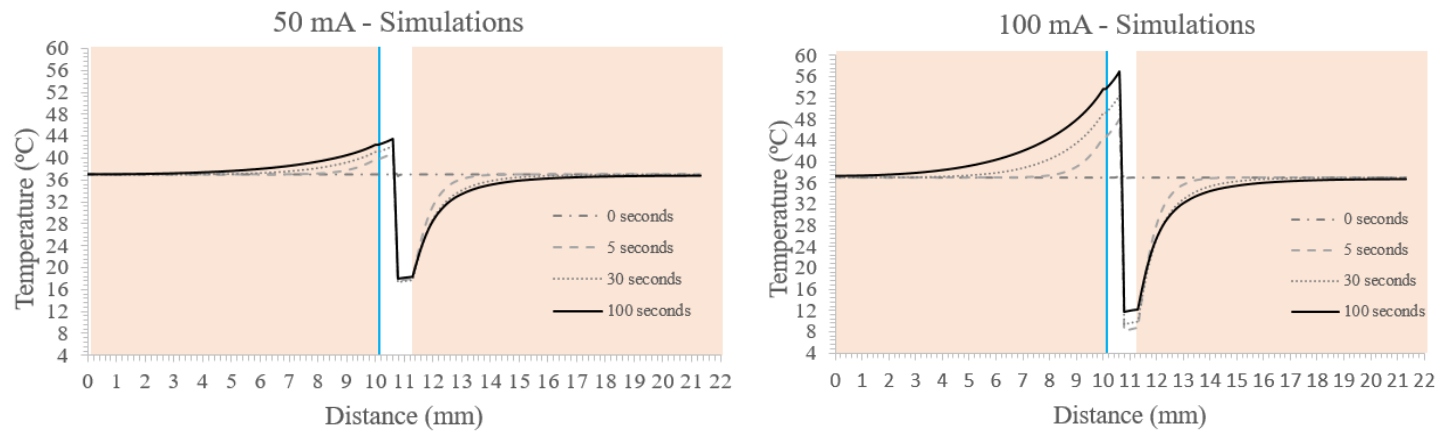

Brain

Aluminum

Figure 8. Temperature variation through A-A' cross-section, considering $50 \mathrm{~mA}$ and $100 \mathrm{~mA}$ currents. . 
increasing the exposure time has more effect on the hot side of the system. Looking now to the $100 \mathrm{~mA}$ plot, the hot side temperatures exceed $43^{\circ} \mathrm{C}$ even after $5 \mathrm{~s}$ exposure time, as expected, allowing to conclude that higher currents are more difficult to control for these applications.

\section{B. Power Requirements.}

Power is one of the most important parameters when building a wireless microsystem, and the microcooler device will probably be the one that requires more energy to work properly. From simulations it was also possible to obtain the electrical potential values between the microcooler feeding pads, and the results are presented in table II.

TABLE II. VALUES OF VOltage ON THE Microcooler DEVICE

\begin{tabular}{|c|c|c|c|}
\hline Current & 5s & 30s & 100s \\
\hline $50 \mathrm{~mA}$ & $1.22 \mathrm{~V}$ & $1.24 \mathrm{~V}$ & $1.25 \mathrm{~V}$ \\
\hline $100 \mathrm{~mA}$ & $2.36 \mathrm{~V}$ & $2.43 \mathrm{~V}$ & $2.49 \mathrm{~V}$ \\
\hline
\end{tabular}

With the values presented in the previous table, it is possible to calculate that for $50 \mathrm{~mA}$ the power consumed by this microcooler device is between $61 \mathrm{~mW}$ and $62.5 \mathrm{~mW}$. For $100 \mathrm{~mA}$, the power consumption is between $236 \mathrm{~mW}$ and $249 \mathrm{~mW}$. These values are higher than usually found on wireless implantable devices, but it doesn't mean that this device can't be powered with that method. As described in [11], in a small implantable device the power delivered to the device can't go above a few $\mathrm{mW}$ while meeting the specific absorption rate (SAR) requirements. To overcome this problem, a small battery will be required to provide energy for discharges, which may be wirelessly recharged between seizures.

\section{B. Antenna measurements.}

After validation by simulation that the commercial peltier is able to cool down to the required temperature, an experimental validation was conducted to assess the performance of the proposed antenna that is intended for wireless power transmission.

The experimental setup implemented is shown in figure 9 . It mainly consists of a glass beaker to hold the water and allow for antenna submersion. The experimental setup is presented in figure 6, alongside its HFSS model, as it was deemed important to consider the effect of water-glass-air interfaces around the antenna in the simulation environment.

With this setup, measurements and simulations were performed. Firstly, the return loss was determined, and then the antenna's radiation pattern in the azimuth plane was obtained, resorting to an anechoic chamber.
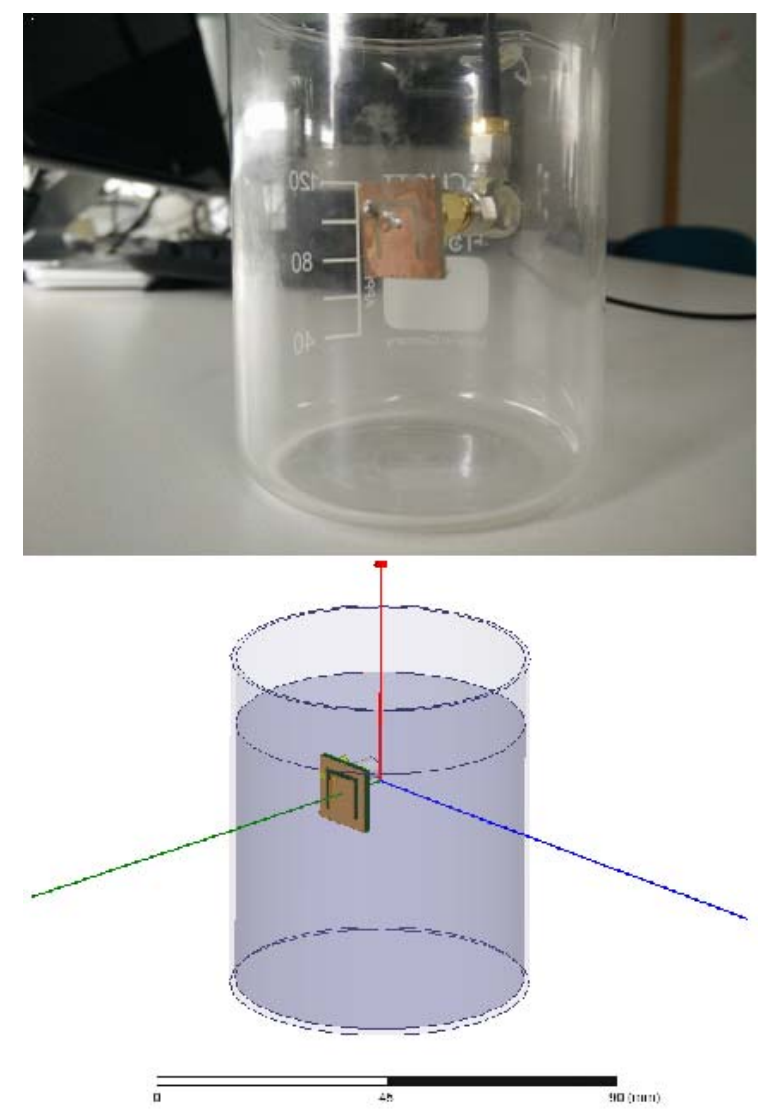

Figure 9. Antenna submersion setup, photograph and model (top and bottom, respectively).

Figure 10 contains the measured and simulated return loss, while figure 11 shows the azimuth plane radiation pattern at $900 \mathrm{MHz}$.

Analyzing the return loss allows us to conclude that the system is capable of accepting power at around $900 \mathrm{MHz}$, and there is an agreement between simulated and measured values, therefore validating our model.

The radiation pattern is determined for the 180 degrees on the frontal side of the antenna, due to limitations on the setup, which didn't allow 360 degree measurements. As it can be seen, the measured and the calculated results agree in both shape and value. The antenna's radiation is directed forward, with around $-10 \mathrm{~dB}$ of gain, while on the sides it goes down to around $-16 \mathrm{~dB}$, which proves to be sufficient for powering a small implant with low power requirements. A small artefact is noted on the measurements at around 60 degrees, as a slight dip occurs, which can be due to reflections happening in the measurement setup, which will be addressed in the future. 


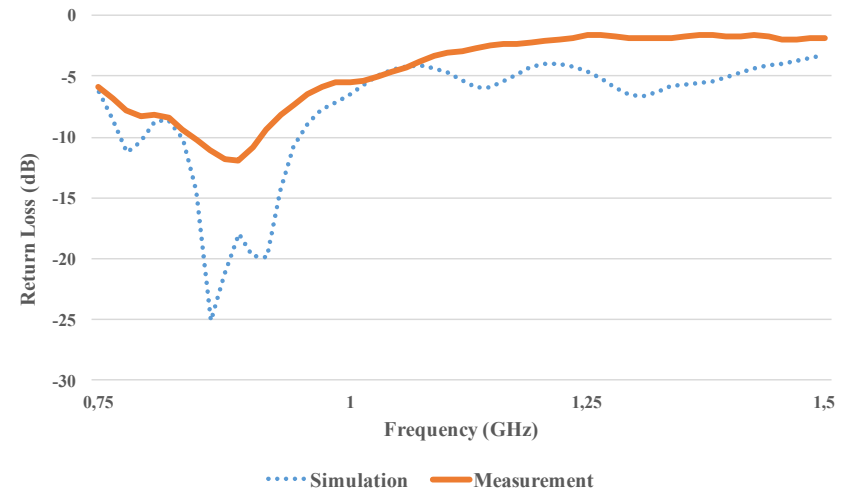

Figure 10. Measured and Simulated return loss.

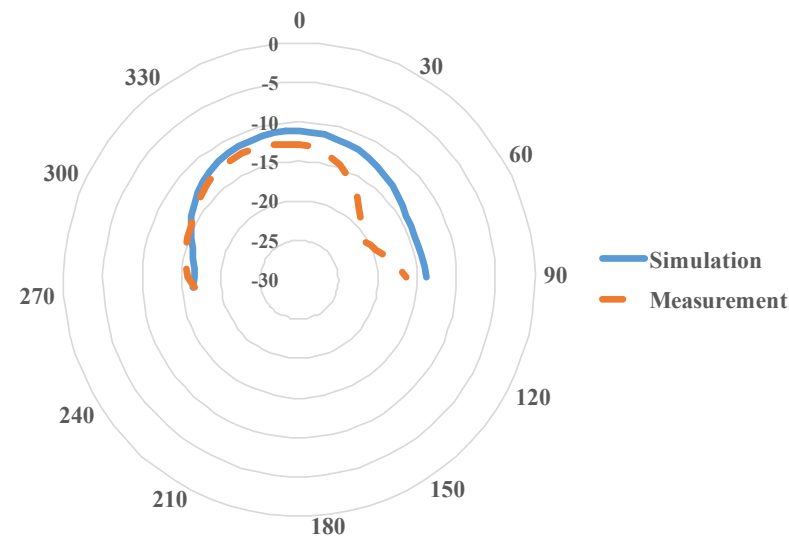

Figure 11. Measured and Simulated radiation pattern over the azimuth plane at $900 \mathrm{MHz}$.

\section{CONCLUSIONS AND Future WorK}

This work shows the proposal for a microdevice to cool down brain cells using a microcooler device. After testing for two different currents, it was possible to conclude that the implemented system is able to cool one millimeter of brain tissue bellow $30^{\circ} \mathrm{C}$, with a current of $50 \mathrm{~mA}$, dissipating only $62.5 \mathrm{~mW}$, while keeping the hot side below safe values. In fact, it was possible to get temperatures near $20^{\circ} \mathrm{C}$ in some brain cells, keeping the hot side below $43^{\circ} \mathrm{C}$. According to [3], this means that the proposed system has the potential to suppress epilepsy seizures without using big external heatsinks, as is common in other works [3]. With these encouraging results, real tests will follow with in vitro cells to verify these results. Finally, the power consumption results lead us to conclude that a small battery will be enough to store the required energy between each discharge. Considering that epilepsy seizures are a not a constant event, the battery could be wirelessly recharged with the necessary energy between each seizure event. Concerning the wireless power module, a first iteration in the path to the final device was presented here, and it has shown inspiring potential due to the $-10 \mathrm{~dB}$ gain the antenna achieves while inside a body of water. As future work, a more complete analysis of its radiation pattern will be made. Additionally, the antenna will be fabricated in a metal sheet, to approximate it even more to the final design, and it will be tested inside a human brain phantom. Finally, as it will be used as a heat sink inside the human body, we will have to evaluate thermal effects on its radiation properties.

\section{REFERENCES}

[1] K. Bazaka. M. V. Jacob, "Implantable Devices: Issues and Challenges", Electronics, 2, 1-34; 2013

[2] Qmed - Qualified Suppliers to the Medical Device Industry: http://www.qmed.com/mpmn/medtechpulse/us-implantabledevicemarket-exceed-50-billion. http://www.ninds.nih.gov/disorders/epilepsy/epilepsy_research.htm

[3] K.S. Patel, et al, "Efficacy of vagus nerve stimulation as a treatment for medically intractable epilepsy in brain tumor patients. A casecontrolled study using the VNS therapy Patient Outcome Registry" Seizure. October ; 22(8): 627-633, 2013.

[4] M. Fujii, H. Fujioka, et al, "Application of Focal Cerebral Cooling for the Treatment of Intractable Epilepsy", Neurol Med Chir (Tokyo) 50, p839-844, 2010.

[5] S. Luan, I. Williams, K. Nikolic, T. G. Constandinou, "Neuromodulation: present and emerging methods" in frontiers in Neuroengineering, Vol. 7, July 2014.

[6] F. Reverter, T. Prodromakis, et al, "Design Considerations for a CMOS Lab-on-Chip Microheater Array to Facilitate the in vitro Thermal Stimulation of Neurons", in Circuits and Systems (ISCAS), 2014 IEEE International Symposium on , vol., no., pp.630-633, 1-5 June 2014

[7] L. Zhu and A. Rosengart, "Cooling penetration into normal and injured brain via intraparenchymal brain cooling probe: theoretical analysis," Heat Transfer Engineering, 29, 284-294 (2008).

[8] Mraovitch, S., C. Iadecola, and D. J. Reis. "Vasoconstriction unassociated with metabolism in cerebral cortex elicited by electrical stimulation of the parabrachial nucleus in rat." J. Cerebral Blood Flow and Metab., 3 (Suppl. 1), S196-S197, 1983.

[9] I. Osorio, F. Chang, N. Gopalsami, "Seizure control with thermal energy? Modeling of heat diffusivity in brain tissue and computerbased design of a prototype mini-cooler” Epilepsy Behav,, pp203-211, Sep 2009

[10] A. Ibrahim, M. Kiani, "Safe Inductive Power Transmission to Millimeter-Sized Implantable Microelectronics Devices" Engineering in Medicine and Biology Society (EMBC), 2015 37th Annual International Conference of the IEEE, 817-820, Aug. 2015. 